\title{
Subjects or Objects? Prisoners and Human Experimentation
}

Barron H. Lerner, M.D., Ph.D.

$\mathrm{D}$ uring the 1950s, inmates at what was then called Holmesburg Prison, in Philadelphia, were inoculated with condyloma acuminatum, cutaneous moniliasis, and viruses causing warts, herpes simplex, and herpes zoster. ${ }^{1}$ For participating in this research, and in studies exposing them to dioxin and agents of chemical warfare, they were paid up to $\$ 1,500$ a month. Between 1963 and 1971, researchers in Oregon and Washington irradiated and repeatedly took biopsy specimens from the testicles of healthy prisoners; the men subsequently reported rashes, peeling, and blisters on the scrotum as well as sexual difficulties. ${ }^{2}$ Hundreds of such experiments induced the federal government to essentially ban research involving prisoners in 1978. The message: such research is fundamentally exploitative and thus unethical.

Yet a recent report by the Institute of Medicine (IOM) has opened the closed door, arguing not only that such research can be performed appropriately but that prisoners deserve to be included in investigative studies - at least those who might benefit directly. Examination of the explanations behind U.S. restrictions on prison research and their current applicability can provide guidance for today's policy debates.

The vulnerability of prisoners to exploitation has long been known. As early as 1906, for instance, critics noted how difficult it would have been for prisoners to refuse to participate in a cholera experiment that ultimately killed 13 men. ${ }^{3}$ Still, investigators periodically sought out "volunteers" among such captive populations, whose institutionalization offered researchers accessible subjects unlikely to be lost to follow-up.

Most such research did not seek to benefit participants. In 1915 , for example, Public Health Service researcher Joseph Goldberger induced pellagra in healthy Mississippi prisoners, who were offered

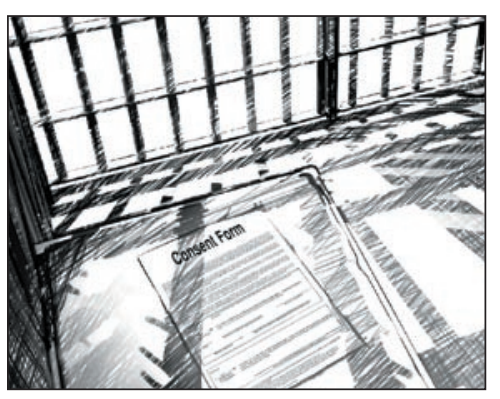

parole in exchange for participation. Those who signed up experienced the very severe symptoms of the disease, including diarrhea, rash, and mental confusion. ${ }^{3}$ Goldberger, however, proved his hypothesis that pellagra was a vitamin-deficiency disease that could be cured by ingestion of the $B$ vitamin now known as niacin. Thanks to this work, as well as the discovery of insulin and the first antimicrobial agents, the years between World War I and World War II were heady times for scientific research.

World War II turned questionable experimentation on prisoners into a cottage industry. As other Americans risked their lives on the battlefield, prisoners did their part by participating in studies that exposed them to gonorrhea, gas gangrene, dengue fever, and malaria. ${ }^{1}$ Any consideration of meaningful consent was subsumed by the war imperative.

Ironically, the biggest boost to such experimentation came as a result of the postwar Nuremberg trial of 20 Nazi doctors, which gave rise to the Nuremberg Code, a set of principles intended to prohibit human experimentation without subjects' consent. When defense lawyers implied that American scientists had conducted wartime research analogous to that of the Nazis, one prosecution witness, Andrew C. Ivy, cited malaria experiments involving Illinois prisoners as an example of "ideal," noncoercive research. Ivy's 1948 publication of his conclusions helped to institutionalize prison experimentation for the next quarter-century. ${ }^{4}$

It was an experiment involving another vulnerable population that halted the prison research enterprise. In 1972, an Associated Press reporter broke the story that poor southern black men with syphilis had been deliberately left untreated for 40 years so researchers could study the natural course of the disease. In the environment created by the civil rights movement and protests against the Vietnam War, such research was condemned. The scandal led to the formation of the National Commission for the Protection of Human Subjects of Biomedical and Behavioral Research and eventually the Belmont Report, which recommended revamping human experimentation using the principles of respect for persons, nonmaleficence, and justice.

In the case of prison research, the new atmosphere proved especially restrictive. In 1978, the Department of Health and Human Services (DHHS) passed regulations that limited federally funded research involving prisoners in several ways, stipulating, for example, that experiments could pose no more than minimal risk 
to the subjects. The overarching concern was that prisons were inherently coercive environments in which informed consent could never be obtained. The fact that research offered financial rewards, alleviation of boredom, and the prospect of earlier parole made it even more dicey.

This was the prevailing view until 2004, when the DHHS asked the IOM to revisit the matter. In August 2006 the IOM published its report, which acknowledged that it might make sense to leave the situation alone. For example, the U.S. prison population includes disproportionate numbers of vulnerable people: members of minority groups, the mentally ill, and persons with HIV infection and other serious infectious diseases. Prisons are generally overcrowded and have inadequate health care services. All these factors suggested that any easing of restrictions might lead to the repetition of previous errors.

Nonetheless, the IOM panel, although sensitive to past "unconscionable abuses," recommended that experiments carrying more than minimal risk be allowed, with the caveat that studies involving drugs or other biomedical interventions be required to have potential benefits for prisoners. The panel also recommended several safeguards, such as creating a public database of prison experiments, limiting research to interventions with some demonstrated safety and efficacy, ensuring that studies include a majority of nonprisoner subjects, and requiring that proposals be vetted by institutional review boards that would include prisoner representatives.

The panel's decision makes sense for several reasons. The first might be termed historical. For most of the 20th century, despite the findings at Nuremberg and occasional other warnings, human experimentation was largely seen as a "good," something that would advance science and benefit health. The backlash against experimentation in prisons occurred during the 1970s, when authority was being questioned throughout society. No mechanisms were in place to ensure the rights of vulnerable subjects. It thus made sense to ban any risky research in prisons.

It is often said that those who ignore history are condemned to repeat it. But a decision to retain current restrictions because of past abuses would ignore several important developments. Since 1978, a network of institutional review boards has been established at the National Institutes of Health, other governmental agencies, and research universities throughout the country. With "informed consent" now common parlance, study subjects are more aware of their rights. And, largely owing to the work of AIDS activists and breast cancer activists, sick and at-risk persons, even those from potentially vulnerable populations, now actively pursue participation in research protocols. Even though not all these developments are unambiguously positive, to ignore them and the opportunities they may afford prisoners would be to regress. As the IOM report said, "Respect for prisoners also requires recognition of their autonomy."

Another argument in favor of relaxing restrictions is that the reflexive assumption that all prison research is problematic may not be accurate. In light of the abuses, critics have understandably argued that human experimentation in prison has failed because it takes place in a coercive environment that vitiates any possibility of informed consent. But that is a theory that can and should be investigated empirically through formal studies of the consent process in prisons. Moreover, as philosopher Carl Cohen has argued, research outside of prisons often has coercive elements as well so to the degree that coercion is involved, it may have little to do with imprisonment. ${ }^{5}$

Finally, reinstituting and then monitoring prison research would afford society an opportunity for ongoing scrutiny and reassessment. Indeed, the IOM panel found that much unregulated prison research was being conducted despite the 1978 guidelines. Many of the notorious prison experiments involved the active deception of study participants - an abuse more easily avoided if the whole enterprise is aboveboard. It is even possible that research studies, by providing a window into prison life, would focus needed attention on deficiencies in prison health care.

Still, the new regulations must be approached with trepidation. As sociologist Erving Goffman showed in his 1961 book Asylums, "total institutions" such as prisons may run roughshod over the rights of their inhabitants. Perhaps this book should be required reading for any investigator who embarks on research within prison walls.

Dr. Lerner is an associate professor of medicine and public health at Columbia University, New York.

1. Hornblum AM. They were cheap and available: prisoners as research subjects in twentieth century America. BMJ 1997;315:1437-41. 2. Welsome E. The plutonium files: America's secret medical experiments in the Cold War. New York: Delta, 1999:362-82.

3. Lederer SE. Subjected to science: human experimentation in America before the Second World War. Baltimore: Johns Hopkins University Press, 1995.

4. Harkness JM. Nuremberg and the issue of wartime experiments on US prisoners: the Green Committee. JAMA 1996;276:1672-5.

5. Cohen C. Medical experimentation on prisoners. Perspect Biol Med 1978;21:357-72. Copyright @ 2007 Massachusetts Medical Society. 